University of Nebraska - Lincoln

DigitalCommons@University of Nebraska - Lincoln

Efficacy of spinosad and methoprene, applied alone or in combination, against six stored-product insect species

Christos G. Athanassiou

University of Thessaly, athanassiou@agr.uth.gr

Frank H. Arthur

USDA-ARS, frank.arthur@ars.usda.gov

Nickolas G. Kavallieratos

Benaki Phytopathological Institute

James E. Throne

USDA-ARS, Manhattan, KS, james.throne@ars.usda.gov

Follow this and additional works at: https://digitalcommons.unl.edu/usdaarsfacpub

Athanassiou, Christos G.; Arthur, Frank H.; Kavallieratos, Nickolas G.; and Throne, James E., "Efficacy of spinosad and methoprene, applied alone or in combination, against six stored-product insect species" (2011). Publications from USDA-ARS / UNL Faculty. 2038.

https://digitalcommons.unl.edu/usdaarsfacpub/2038

This Article is brought to you for free and open access by the U.S. Department of Agriculture: Agricultural Research Service, Lincoln, Nebraska at DigitalCommons@University of Nebraska - Lincoln. It has been accepted for inclusion in Publications from USDA-ARS / UNL Faculty by an authorized administrator of DigitalCommons@University of Nebraska - Lincoln. 


\title{
Efficacy of spinosad and methoprene, applied alone or in combination, against six stored-product insect species
}

\author{
Christos G. Athanassiou - Frank H. Arthur • \\ Nickolas G. Kavallieratos · James E. Throne
}

Received: 5 May 2010/ Accepted: 19 July 2010/Published online: 16 October 2010

(C) Springer-Verlag 2010

\begin{abstract}
Efficacy of the insecticides spinosad and methoprene, applied alone or in combination to wheat, was evaluated against six stored-product insect species, Rhyzopertha dominica, Sitophilus oryzae, S. granarius, Cryptolestes ferrugineus, Oryzaephilus surinamensis, and Liposcelis bostrychophila. The concentrations of the insecticides were 0.1 and $0.5 \mathrm{ppm}$ for spinosad and 1 and $5 \mathrm{ppm}$ for methoprene. Parental mortality of $R$. dominica was $100 \%$ on wheat treated with either rate of spinosad, with no progeny production in any combination treatment. Parental mortality of $S$. oryzae did not exceed $62 \%$, and progeny production was not reduced by any insecticide treatment. All $S$. granarius adults exposed on wheat treated with spinosad alone at $0.5 \mathrm{ppm}$ were killed, but parental mortality was reduced when methoprene was added. Progeny production was reduced in treatments containing spinosad. Mortality of adult C. ferrugineus was $97 \%$ or greater in treatments containing spinosad, but adult mortality of $O$. surinamensis and L. bostrychophila was not
\end{abstract}

Communicated by M. Traugott.

C. G. Athanassiou ( $\square)$

Laboratory of Entomology and Agricultural Zoology,

Department of Agriculture, Crop Production and Rural

Development, University of Thessaly, Phytokou str.,

N. Ionia, 38443 Magnisia, Greece

e-mail: athanassiou@agr.uth.gr

F. H. Arthur - J. E. Throne

USDA-ARS Center for Grain and Animal Health Research,

1515 College Avenue, Manhattan, KS 66502-2736, USA

N. G. Kavallieratos

Laboratory of Agricultural Entomology,

Department of Entomology and Agricultural Zoology, Benaki

Phytopathological Institute, 8 Stefanou Delta str., Kifissia, 14561

Attica, Greece reduced by insecticide treatments. The specific combinations of spinosad and methoprene evaluated in our study would have no benefit over spinosad used alone for control of any of the six species tested.

Keywords Grain protectants - Spinosad $\cdot$ Methoprene · Stored-product insects

\section{Introduction}

The lesser grain borer, Rhyzopertha dominica (L.) (Coleoptera: Bostrychidae), is the major pest of wheat in most of the world, and it has developed resistance to some of the insecticides used for its control (Arthur 1996, 2004; Daglish 2008). The bacterial insecticide spinosad provides complete control of this species, but does not control some of the other insect pests of wheat (Daglish 2008). Thus, combination treatments of insecticides that include spinosad and would control other insect pests of stored wheat would be desirable. Methoprene, an insect growth regulator (IGR), is not always effective for control of $R$. dominica, but it is effective for control of some of the other pests of stored wheat because it can completely suppress progeny production in externally feeding pests such as the rusty grain beetle, Cryptolestes ferrugineus (Stephens) (Coleoptera: Laemophloeidae) (Daglish 2008), and the sawtoothed grain beetle, Oryzaephilus surinamensis (L.) (Coleoptera: Silvanidae). Nevertheless, methoprene is ineffective against the rice weevil, Sitophilus oryzae (L.) (Coleoptera: Curculionidae) (Daglish 2008).

Spinosad has been evaluated against the major insect pests of stored grains (Subramanyam et al. 2007; Athanassiou et al. 2008a, b, c; Chintzoglou et al. 2008). Although spinosad is registered in the USA at a label rate 
of $1 \mathrm{ppm}$ on stored grains, it is not yet being marketed in the USA. This rate of $1 \mathrm{ppm}$ will kill adults and limit progeny production of several major stored-grain insect pests, including $R$. dominica, Prostephanus truncatus (Horn) (Coleoptera: Bostrychidae), and S. oryzae (Fang et al. 2002a, b; Athanassiou et al. 2008a, b, c; Kavallieratos et al. 2010). However, 1 ppm spinosad will not completely control red flour beetle, Tribolium castaneum (Herbst) (Coleoptera: Tenebrionidae), confused flour beetle, Tribolium confusum Jacquelin du Val, $O$. surinamensis, C. ferrugineus, or psocids such as Liposcelis bostrychophila (Badonnel) (Psocoptera: Liposcelididae), but will generally eliminate progeny production by these species (Fang et al. 2002a, b; Athanassiou et al., 2008b, 2009; Daglish 2008).

Insect growth regulators are used in many insect pest management programs for agricultural and urban entomology. Currently only the IGR methoprene is used as a grain protectant, with application rates ranging from 1 to 5 ppm (Arthur 2004; Daglish and Wallbank 2005). Methoprene is a juvenile hormone analogue, which affects development of immature insects, can have ovicidal effects, and also can cause sub-lethal effects such as reduced adult fecundity in insects exposed as immatures (Oberlander et al. 1997) or adults (Daglish and Pulvirenti 1997). Several studies document effectiveness of methoprene against many stored-grain insect species, including $R$. dominica, $C$. ferrugineus, and $O$. surinamensis, but it does not control Sitophilus species (Nayak et al. 1998; Arthur 2004; Chanbang et al. 2007, 2008; Daglish 2008).

Stored grain insects can coexist within a storage bin, and hence a binary combination of insecticides may give more complete control than the application of a single insecticide, especially when mortality from the individual components is not complete or progeny production occurs even when parental adults are killed, as has been shown with spinosad on different grains (Fang et al. 2002a; Athanassiou et al. 2008c; Chintzoglou et al. 2008). Conversely, methoprene affects progeny production, but generally adults are not affected (Arthur 2004; Daglish 2008). Hence, a combination of these insecticides may be more effective than the application of each insecticide alone, and may also allow for a reduction in insecticide concentration of the respective components. Daglish (2008) examined binary combinations of several insecticides, including spinosad and methoprene applied at 1 and $0.6 \mathrm{ppm}$, respectively, alone and in combination. Also, Nayak and Daglish (2007) noted that a combined treatment of spinosad and chlorpyriphos-methyl controlled adults and suppressed progeny production of four species of the genus Liposcelis. The objective of our study was to evaluate binary combinations of spinosad and methoprene, using lower rates of spinosad ( 0.1 and $0.5 \mathrm{ppm})$ in combination with 1 and 5 ppm methoprene, which are the upper and lower label rates for methoprene in the USA. We used these lower rates of spinosad to determine if even small amounts of spinosad combined with methoprene would improve the control of different stored grain species, including those species that are not controlled by either methoprene or spinosad. We used lower rates of spinosad, rather than methoprene, because the anticipated cost of spinosad in the U.S. is expected to exceed that of methoprene. Test insect species were three primary internally feeding pests: $R$. dominica, S. oryzae, and Sitophilus granarius (L.), and three secondary externally feeding pests: C. ferrugineus, O. surinamensis, and L. bostrychophila.

\section{Materials and methods}

Commodities and formulations

The wheat used in the experiment was untreated, clean, and a mixture of the soft wheat varieties Fuller and Santa Fe, with moisture content adjusted to $13.5 \%$ (by adding water) before the test. The insecticide formulations were spinosad NAF 313 (13\% active ingredient [AI]) obtained from Dow AgroSciences (Indianapolis, IN, USA) and methoprene Diacon II (33.6\% [AI]) obtained from Central Sciences International (Schaumburg, IL, USA).

\section{Insects}

Rhyzopertha dominica, S. oryzae, and S. granarius were reared on whole wheat at $27.5^{\circ} \mathrm{C}$ and $75 \%$ r.h. Cryptolestes ferrugineus and $O$. surinamensis were reared on rolled oats with $5 \%$ brewer's yeast, at the same environmental conditions as above. Liposcelis bostrychophila was reared on a mixture of $97 \%$ cracked wheat kernels, $2 \%$ rice krispies, and $1 \%$ brewer's yeast at $30^{\circ} \mathrm{C}$ and $70 \%$ r.h. (Opit and Throne 2008). Adults of all beetle species were mixed-sex and $<4$-weeks-old. In tests involving L. bostrychophila, which is almost exclusively parthenogenetic, only females $<3$-weeks-old were used, following procedures described by Opit and Throne (2008). Briefly, adult psocid females were allowed to oviposit in 35-mm Petri dishes containing $1 \mathrm{~g}$ of diet, and then these females were removed to obtain progeny of known age. All insects were taken from cultures maintained in the Stored Product Insect Research Unit (SPIRU) at the Center for Grain and Animal Health Research (CGAHR), USDA-ARS, Manhattan, KS.

\section{Bioassays}

Individual replicate lots of $500 \mathrm{~g}$ of wheat were placed in 0.47-1 cylindrical glass jars for the nine insecticide treatments: untreated controls sprayed only with distilled water, $0.1 \mathrm{ppm}$ spinosad, $0.5 \mathrm{ppm}$ spinosad, $1 \mathrm{ppm}$ methoprene, 
5 ppm methoprene, $0.1 \mathrm{ppm}$ spinosad $+1 \mathrm{ppm}$ methoprene, $0.1 \mathrm{ppm}$ spinosad $+5 \mathrm{ppm}$ methoprene, $0.5 \mathrm{ppm}$ spinosad $+1 \mathrm{ppm}$ methoprene, and $0.5 \mathrm{ppm}$ spinosad +5 ppm methoprene. We used a Badger 100 artist's airbrush (Badger Air-Brush Company, Franklin Park, IL, USA) to treat each lot of wheat with $0.35 \mathrm{ml}$ of formulated solution. Before spraying, the wheat was spread into a monolayer, in order to maximize insecticide distribution. After each lot was treated, it was placed back in the jar, and the jar was shaken manually for $30 \mathrm{~s}$ to further improve equal distribution of the insecticide(s). From each jar, three 20-g samples were taken and placed in cylindrical plastic vials $(3 \mathrm{~cm}$ in diameter, $8 \mathrm{~cm}$ in height). The vials had a plastic lid with a hole in the center covered with fine mesh, while the internal "neck" of the vials was covered by Fluon (Northern Products, Woonsocket, RI, USA). Ten adults of each species were placed in each vial, using separate vials for each species. Vials were placed in black plastic boxes with saturated solutions of $\mathrm{NaCl}$ to maintain $75 \%$ r.h. (Greenspan 1977; Opit and Throne 2008), and boxes were placed in incubators set at $27.5^{\circ} \mathrm{C}$ and $75 \%$ r.h. After 14 days, vials were opened, adults were removed from the vials, mortality was recorded, and the adults were discarded. The vials were returned to the incubators at the same environmental conditions described above. Progeny production for L. bostrychophila and the beetle species was assessed after 45 and 65 days, respectively. Psocid nymphs and adults were counted separately. Few larvae of $C$. ferrugineus and $O$. surinamensis were found, so their number was added to the adult progeny counts. Only adults were counted for $R$. dominica and the Sitophilus spp. because immatures occur inside the wheat kernels. The entire procedure was replicated thrice by preparing new lots of treated wheat for each replicate, and exposing, counting, and recording data for adult mortality and progeny as described above.

Data analysis

The mortality and progeny production counts were analyzed separately for each species by using a one-way ANOVA to test for differences among treatments, with JMP software (Sall et al. 2001). For L. bostrychophila, adult and immature progeny (nymphs) data were analyzed separately. Means were separated by the Tukey-Kramer (HSD) test, at 0.05 probability (Sokal and Rohlf 1995).

\section{Results}

Mortality

The presence of spinosad, alone or in combination with methoprene, resulted in complete mortality of $R$. dominica, even at the lowest concentration of spinosad (Table 1), but mortality on wheat treated with methoprene alone did not differ from that on untreated wheat. Mortality of $S$. oryzae was greater on wheat treated with spinosad at $0.5 \mathrm{ppm}$, alone or in combination with methoprene, than in the other treatments, but did not exceed $62 \%$ (Table 2). Mortality of S. granarius was $100 \%$ only in wheat treated with $0.5 \mathrm{ppm}$ of spinosad alone (Table 3).

Among the externally feeding pests, mortality was higher for $C$. ferrugineus than for the other species. For this species, mortality in treatments that included spinosad at $0.5 \mathrm{ppm}$ was significantly higher than in the other treatments, and exceeded $97 \%$ (Table 4). For O. surinamensis, the application of the insecticides did not increase adult mortality in comparison with the control, and mortality did not exceed 33\% (Table 5). For L. bostrychophila, significant differences were noted among treatments, but mortality did not exceed $22 \%$ (Table 6).

\section{Progeny production}

For $R$. dominica, adult progeny emergence was significantly reduced in all of the treatments, in comparison with progeny emergence in the untreated wheat, and never exceeded 1.1 progeny (Table 1 ). In contrast, no differences were found in $S$. oryzae progeny production in the treated and the untreated wheat, regardless of insecticide or concentration (Table 2). Progeny production was high and ranged between 154 and 221 adults/vial. However,

Table 1 Mean mortality ( $\% \pm \mathrm{SE})$ and progeny production (adults/ vial $\pm \mathrm{SE}$ ) of $R$. dominica on wheat treated with two concentrations of spinosad and two concentrations of methoprene, applied alone or in combination

\begin{tabular}{lll}
\hline Treatment & Mortality & Progeny \\
\hline Control & $3.3 \pm 1.7 \mathrm{~b}$ & $128.3 \pm 19.2 \mathrm{a}$ \\
Spinosad 0.1 ppm & $100.0 \pm 0.0 \mathrm{a}$ & $1.1 \pm 0.4 \mathrm{~b}$ \\
Spinosad 0.5 ppm & $100.0 \pm 0.0 \mathrm{a}$ & $0.1 \pm 0.1 \mathrm{~b}$ \\
Methoprene $1 \mathrm{ppm}$ & $2.2 \pm 1.5 \mathrm{~b}$ & $0.0 \pm 0.0 \mathrm{~b}$ \\
Methoprene $5 \mathrm{ppm}$ & $5.6 \pm 3.0 \mathrm{~b}$ & $0.2 \pm 0.1 \mathrm{~b}$ \\
Spinosad 0.1 ppm + methoprene & $100.0 \pm 0.0 \mathrm{a}$ & $0.0 \pm 0.0 \mathrm{~b}$ \\
$\quad 1$ ppm & & \\
Spinosad 0.1 ppm + methoprene & $100.0 \pm 0.0 \mathrm{a}$ & $0.0 \pm 0.0 \mathrm{~b}$ \\
$\quad 5$ ppm & & \\
Spinosad 0.5 ppm + methoprene & $100.0 \pm 0.0 \mathrm{a}$ & $0.0 \pm 0.0 \mathrm{~b}$ \\
$\quad 1$ ppm & & \\
Spinosad 0.5 ppm + methoprene & $100.0 \pm 0.0 \mathrm{a}$ & $0.0 \pm 0.0 \mathrm{~b}$ \\
5 ppm & & \\
$F$ & 1536.8 & 45.1 \\
$P$ & $<0.01$ & $<0.01$ \\
\hline
\end{tabular}

Within each column, means followed by the same letter are not significantly different; in all cases $\mathrm{df}=8,72$, Tukey-Kramer (HSD) test at $P<0.05$ 
Table 2 Mean mortality ( $\% \pm \mathrm{SE}$ ) and progeny production (adults/ vial $\pm \mathrm{SE}$ ) of $S$. oryzae on wheat treated with two concentrations of spinosad and two concentrations of methoprene, applied alone or in combination

\begin{tabular}{lll}
\hline Treatment & Mortality & Progeny \\
\hline Control & $4.4 \pm 2.4 \mathrm{c}$ & $221.6 \pm 11.2$ \\
Spinosad 0.1 ppm & $2.2 \pm 1.5 \mathrm{c}$ & $177.4 \pm 25.2$ \\
Spinosad 0.5 ppm & $57.8 \pm 7.4 \mathrm{a}$ & $189.8 \pm 23.6$ \\
Methoprene 1 ppm & $5.6 \pm 2.4 \mathrm{c}$ & $193.6 \pm 5.9$ \\
Methoprene 5 ppm & $2.2 \pm 1.5 \mathrm{c}$ & $154.5 \pm 24.5$ \\
Spinosad 0.1 ppm + methoprene 1 ppm & $1.1 \pm 1.1 \mathrm{c}$ & $160.3 \pm 19.0$ \\
Spinosad 0.1 ppm + methoprene 5 ppm & $3.3 \pm 1.7 \mathrm{c}$ & $170.4 \pm 11.5$ \\
Spinosad 0.5 ppm + methoprene 1 ppm & $23.5 \pm 7.8 \mathrm{~b}$ & $164.7 \pm 12.0$ \\
Spinosad 0.5 ppm + methoprene 5 ppm & $61.1 \pm 5.9 \mathrm{a}$ & $173.3 \pm 17.5$ \\
$F$ & 36.5 & 1.3 \\
$P$ & $<0.01$ & 0.27 \\
\hline
\end{tabular}

Within each column, means followed by the same letter are not significantly different; in all cases $\mathrm{df}=8,72$, Tukey-Kramer (HSD) test at $P<0.05$; where no letters exist, no significant differences were noted

significant differences were noted among treatments for $S$. granarius, but progeny production was not completely suppressed (Table 3). For this species, adult emergence was significantly lower on wheat treated with $0.5 \mathrm{ppm}$ of spinosad applied alone or in combination with $5 \mathrm{ppm}$ of methoprene, in comparison with the other treatments.

There were no $C$. ferrugineus progeny produced in treated wheat, but only 3.1 progeny were produced in untreated wheat (Table 4). Similarly, O. surinamensis progeny production was low in both treated and untreated grains (Table 5). For this reason, no statistical comparisons were carried out for $C$. ferrugineus and $O$. surinamensis progeny production because any conclusions would be biologically meaningless. With the exception of spinosad at $0.1 \mathrm{ppm}$, production of adult progeny of $L$. bostrychophila was reduced in comparison with the untreated wheat (Table 6). However, treatments did not reduce production of nymphs relative to that in untreated wheat.

\section{Discussion}

Spinosad applied at 0.1 and $0.5 \mathrm{ppm}$ resulted in $100 \%$ mortality of parental $R$. dominica, and nearly eliminated progeny production. Addition of methoprene to the spinosad resulted in no progeny. A number of recent studies document susceptibility of $R$. dominica at application rates of $1 \mathrm{ppm}$ spinosad or lower (Athanassiou et al. 2008a, b, c). Chanbang et al. (2007) showed that methoprene suppressed progeny production. If $R$. dominica is the sole species present in a grain storage facility and spinosad is
Table 3 Mean mortality ( $\% \pm \mathrm{SE}$ ) and progeny production (adults/ vial $\pm \mathrm{SE}$ ) of $S$. granarius on wheat treated with two concentrations of spinosad and two concentrations of methoprene, applied alone or in combination

\begin{tabular}{lll}
\hline Treatment & Mortality & Progeny \\
\hline Control & $1.1 \pm 1.1 \mathrm{c}$ & $134.2 \pm 8.4 \mathrm{a}$ \\
Spinosad 0.1 ppm & $3.3 \pm 1.7 \mathrm{c}$ & $109.2 \pm 9.4 \mathrm{a}$ \\
Spinosad 0.5 ppm & $100 \pm 0.0 \mathrm{a}$ & $8.6 \pm 2.6 \mathrm{c}$ \\
Methoprene 1 ppm & $1.1 \pm 1.1 \mathrm{c}$ & $119.0 \pm 7.2 \mathrm{a}$ \\
Methoprene 5 ppm & $4.4 \pm 2.9 \mathrm{c}$ & $103.1 \pm 11.7 \mathrm{ab}$ \\
Spinosad 0.1 ppm + methoprene & $3.3 \pm 2.4 \mathrm{c}$ & $121.3 \pm 6.5 \mathrm{a}$ \\
$\quad 1$ ppm & & \\
Spinosad 0.1 ppm + methoprene & $5.6 \pm 2.4 \mathrm{c}$ & $93.7 \pm 11.8 \mathrm{ab}$ \\
5 ppm & & \\
Spinosad 0.5 ppm + methoprene & $65.6 \pm 11.9 \mathrm{~b}$ & $62.2 \pm 15.4 \mathrm{~b}$ \\
$\quad 1$ ppm & & \\
Spinosad 0.5 ppm + methoprene & $96.7 \pm 2.4 \mathrm{a}$ & $17.8 \pm 3.6 \mathrm{c}$ \\
5 ppm & & \\
$F$ & 97.2 & 24.0 \\
$P$ & $<0.01$ & $<0.01$ \\
\hline
\end{tabular}

Within each column, means followed by the same letter are not significantly different; in all cases $\mathrm{df}=8,72$, Tukey-Kramer (HSD) test at $P<0.05$

Table 4 Mean mortality ( $\% \pm \mathrm{SE}$ ) and progeny production (adults/ vial $\pm \mathrm{SE}$ ) of $C$. ferrugineus on wheat treated with two concentrations of spinosad and two concentrations of methoprene, applied alone or in combination

\begin{tabular}{lll}
\hline Treatment & Mortality & Progeny \\
\hline Control & $26.7 \pm 5.8 \mathrm{c}$ & $3.1 \pm 1.3$ \\
Spinosad 0.1 ppm & $86.7 \pm 3.3 \mathrm{~b}$ & $0.0 \pm 0.0$ \\
Spinosad 0.5 ppm & $97.8 \pm 2.2 \mathrm{a}$ & $0.0 \pm 0.0$ \\
Methoprene 1 ppm & $37.8 \pm 9.7 \mathrm{c}$ & $0.0 \pm 0.0$ \\
Methoprene 5 ppm & $24.4 \pm 7.1 \mathrm{c}$ & $0.0 \pm 0.0$ \\
Spinosad 0.1 ppm + methoprene 1 ppm & $80.0 \pm 5.8 \mathrm{~b}$ & $0.0 \pm 0.0$ \\
Spinosad 0.1 ppm + methoprene 5 ppm & $90.0 \pm 2.9 \mathrm{~b}$ & $0.0 \pm 0.0$ \\
Spinosad 0.5 ppm + methoprene 1 ppm & $98.9 \pm 1.1 \mathrm{a}$ & $0.0 \pm 0.0$ \\
Spinosad 0.5 ppm + methoprene 5 ppm & $98.9 \pm 1.1 \mathrm{a}$ & $0.0 \pm 0.0$ \\
$F$ & 38.8 & \\
$P$ & $<0.01$ & \\
\hline
\end{tabular}

Within each column, means followed by the same letter are not significantly different; in all cases $\mathrm{df}=8,72$, Tukey-Kramer (HSD) test at $P<0.05$. Data for progeny production were not analyzed statistically because of low numbers of progeny produced in the controls

available for use on the stored grain, there appears to be little advantage in using a combination of spinosad and methoprene.

Methoprene generally does not affect progeny production of Sitophilus species because females oviposit into the kernel, and immatures are protected from any insecticide residues that are outside the kernel (Edwards and Short 1984; 
Oberlander et al. 1997; Daglish 2008). Hence, for a contact insecticide to be effective, it must kill Sitophilus adults before they mate or before females oviposit. In our test, parental survival of S. oryzae did not exceed $62 \%$ in any treatment with spinosad, and progeny production was not impacted by any insecticide treatment. However, even when parental mortality of S. granarius was $100 \%$, as occurred at the rate of $0.5 \mathrm{ppm}$ of spinosad applied alone, some progeny were still produced, suggesting delayed mortality of adults but no prevention of oviposition (Getchell and Subramanyam 2008). Parental mortality was less in the combination treatments compared to spinosad alone, suggesting a possible detrimental effect of methoprene on the toxicity of

Table 5 Mean mortality $(\% \pm \mathrm{SE})$ and progeny production (adults/ vial $\pm \mathrm{SE}$ ) of $O$. surinamensis on wheat treated with two concentrations of spinosad and two concentrations of methoprene, applied alone or in combination

\begin{tabular}{lll}
\hline Treatment & Mortality & Progeny \\
\hline Control & $10.0 \pm 2.9$ & $2.3 \pm 1.1$ \\
Spinosad 0.1 ppm & $12.2 \pm 4.0$ & $1.3 \pm 0.8$ \\
Spinosad 0.5 ppm & $24.4 \pm 7.1$ & $4.8 \pm 1.6$ \\
Methoprene 1 ppm & $17.8 \pm 7.2$ & $0.0 \pm 0.0$ \\
Methoprene 5 ppm & $26.7 \pm 8.8$ & $0.0 \pm 0.0$ \\
Spinosad 0.1 ppm + methoprene 1 ppm & $32.2 \pm 9.4$ & $0.0 \pm 0.0$ \\
Spinosad 0.1 ppm + methoprene 5 ppm & $25.6 \pm 6.9$ & $0.0 \pm 0.0$ \\
Spinosad 0.5 ppm + methoprene 1 ppm & $21.1 \pm 5.1$ & $0.0 \pm 0.0$ \\
Spinosad 0.5 ppm + methoprene 5 ppm & $23.3 \pm 9.4$ & $0.0 \pm 0.0$ \\
$F$ & 1.0 & \\
$P$ & 0.44 & \\
\hline
\end{tabular}

Absence of letters in mortality indicates that no significant differences were noted. Data for progeny production were not analyzed statistically because of low numbers of progeny produced in the controls spinosad to this species. Daglish (2008) reported parental mortality for $S$. oryzae of $30 \%$ when exposed to $1 \mathrm{ppm}$ of spinosad compared to $17.3 \%$ mortality of $1 \mathrm{ppm}$ spino$\mathrm{sad}+0.6 \mathrm{ppm}$ methoprene. Although the rates of methoprene used in our study were higher than used by Daglish (2008), this reduction in mortality in combination treatments would seem to indicate a potential issue with using methoprene if Sitophilus species are the target insect pests.

Both $C$. ferrugineus and $O$. surinamensis are external feeders, so all life stages would be exposed to residues of any contact insecticides. The application rates of 0.1 and $0.5 \mathrm{ppm}$ spinosad gave 83 and $100 \%$ mortality of C. ferrugineus at 0.1 and $0.5 \mathrm{ppm}$, respectively, on spinosad-treated maize (Huang and Subramanyam 2007). In our study, we did not achieve $100 \%$ mortality of $C$. ferrugineus, but treatments containing $0.5 \mathrm{ppm}$ spinosad had $97 \%$ or greater mortality. Although no progeny were produced in treated wheat, only 3.1 progeny were produced in untreated wheat so our results on progeny production are inconclusive. External feeders are often unable to develop on unbroken kernels. We cleaned our wheat before the experiments, which probably resulted in the poor progeny production by $C$. ferrugineus and $O$. surinamensis.

Oryzaephilus surinamensis is considered one of the most tolerant stored-product insect species to spinosad (Fang et al. 2002a; Nayak et al. 2005; Huang and Subramanyam 2007; Daglish 2008). Huang and Subramanyam (2007) found that mortality of $O$. surinamensis adults in maize was 5 and $62 \%$, at 0.1 and $0.5 \mathrm{ppm}$, respectively, while mortality reached $100 \%$ only at $2 \mathrm{ppm}$. Thus, higher spinosad doses are required for a satisfactory level of control of this species. Although progeny production was suppressed in some of the treatments containing methoprene in our study, results are again inconclusive because only 2.3 progeny

Table 6 Mean mortality $(\% \pm \mathrm{SE}$ ) and progeny production (adults or nymphs/vial $\pm \mathrm{SE}$ ) of L. bostrychophila on wheat treated with two concentrations of spinosad and two concentrations of methoprene, applied alone or in combination

\begin{tabular}{llll}
\hline Treatment & Mortality & Progeny (adults) & Progeny (nymphs) \\
\hline Control & $0.0 \pm 0.0 \mathrm{~b}$ & $15.1 \pm 2.3 \mathrm{a}$ & $17.4 \pm 2.5 \mathrm{ab}$ \\
Spinosad 0.1 ppm & $1.1 \pm 1.1 \mathrm{~b}$ & $15.3 \pm 3.7 \mathrm{a}$ & $15.2 \pm 3.6 \mathrm{ab}$ \\
Spinosad 0.5 ppm & $21.1 \pm 5.4 \mathrm{a}$ & $6.7 \pm 2.1 \mathrm{~b}$ & $6.4 \pm 1.8 \mathrm{~b}$ \\
Methoprene 1 ppm & $5.6 \pm 2.9 \mathrm{~b}$ & $0.0 \pm 0.0 \mathrm{~b}$ & $18.9 \pm 5.2 \mathrm{ab}$ \\
Methoprene 5 ppm & $7.8 \pm 3.2 \mathrm{~b}$ & $0.0 \pm 0.0 \mathrm{~b}$ & $20.1 \pm 2.8 \mathrm{a}$ \\
Spinosad 0.1 ppm + methoprene 1 ppm & $12.2 \pm 2.2 \mathrm{ab}$ & $1.4 \pm 0.8 \mathrm{~b}$ & $18.6 \pm 1.9 \mathrm{ab}$ \\
Spinosad 0.1 ppm + methoprene 5 ppm & $4.5 \pm 2.4 \mathrm{~b}$ & $0.8 \pm 0.4 \mathrm{~b}$ & $16.1 \pm 1.7 \mathrm{ab}$ \\
Spinosad 0.5 ppm + methoprene 1 ppm & $8.9 \pm 3.1 \mathrm{ab}$ & $0.1 \pm 0.1 \mathrm{~b}$ & $10.3 \pm 2.8 \mathrm{ab}$ \\
Spinosad 0.5 ppm + methoprene 5 ppm & $5.6 \pm 2.4 \mathrm{~b}$ & $0.1 \pm 0.1 \mathrm{~b}$ & $8.1 \pm 1.4 \mathrm{ab}$ \\
$F$ & 4.8 & 15.6 & 3.1 \\
$P$ & $<0.01$ & $<0.01$ & $<0.01$ \\
\hline
\end{tabular}

Within each column, means followed by the same letter are not significantly different; in all cases df $=8,72$, Tukey-Kramer (HSD) test at $P<0.05$ 
were produced in untreated wheat. Oryzaephilus surinamensis also does not develop well on whole-kernel wheat.

Nayak et al. (2005) evaluated spinosad against four psocid species, L. bostrychophila, L. decolor (Pearman), L. entomophila (Enderlein), and L. paeta Pearman on wheat, and found that $1 \mathrm{ppm}$ was effective against L. entomophila, but not against the other species. Athanassiou et al. (2009) reported mortality for L. entomophila after 14 days of exposure in wheat, rice, and maize treated with $1 \mathrm{ppm}$ spinosad of 76,46 , and $76 \%$, respectively. In the same study, the authors noted that complete mortality and progeny production suppression was achieved by the application of chlorpyriphos-methyl with deltamethrin. Similarly, Nayak and Daglish (2007) found that the combination of chlorpyriphos-methyl with spinosad was effective against four Liposcelis species. Nevertheless, reduced rates of spinosad may assist resistance development by the exposed individuals; hence, these rates are not recommended in the case of the application of spinosad alone. On the other hand, the simultaneous use of spinosad with an organophosphorous insecticide, may provide a complementary effect (Nayak and Daglish 2007; Daglish 2008). Methoprene was ineffective against L. bostrychophila, L. entomophila, and L. paeta, and a survey of field populations of L. bostrychophila and L. entomophila indicated that this tolerance occurs naturally and it is not related to resistance (Nayak et al. 1998). In our experiments, methoprene reduced adult progeny production in comparison with the application of spinosad alone, but numbers of progeny nymphs were comparable to those in the untreated wheat. This may indicate that although reproduction and oviposition of L. bostrychophila were not affected by the presence of methoprene, a delay in immature development and disruption in metamorphosis could occur. Additional investigation with longer exposure intervals is needed to examine lethal and sub-lethal effects when L. bostrychophila nymphs are exposed to methoprene.

In conclusion, the specific combinations of spinosad and methoprene evaluated in our study would have no benefit over spinosad used alone for control of any of the six species tested. Spinosad did not provide adequate control of S. oryzae, O. surinamensis, or L. bostrychophila, so it may be advisable to further evaluate combinations of spinosad with another insecticide that is suitable for control of these three species. Spinosad has the advantage of being one of the few insecticides registered for stored grain that is suitable for control of $R$. dominica, the most important insect pest of wheat.

Acknowledgments We thank Ann Redmon and Ngunza Kisangani for technical support, and Patrick Collins for his comments on an early draft of this manuscript. We also thank Wellmark International (Schaumburg, IL, USA) for providing the methoprene. Mention of trade names or commercial products in this publication is solely for the purpose of providing specific information and does not imply recommendation or endorsement by the United States Department of Agriculture, the University of Thessaly, or the Benaki Phytopathological Institute.

\section{References}

Arthur FH (1996) Grain protectants: current status and prospects for the future. J Stored Prod Res 32:293-302

Arthur FH (2004) Evaluation of methoprene alone and in combination with diatomaceous earth to control Rhyzopertha dominica (Coleoptera: Bostrichidae) on stored wheat. J Stored Prod Res 40:485-498

Athanassiou CG, Kavallieratos NG, Chintzoglou GJ (2008a) Effectiveness of spinosad dust against different European populations of the confused flour beetle, Tribolium confusum Jacquelin du Val. J Stored Prod Res 44:47-51

Athanassiou CG, Kavallieratos NG, Yiatilis AE, Vayias BJ, Mavrotas CS, Tomanović Ž (2008b) Influence of temperature and humidity on the efficacy of spinosad against four stored grain beetle species. J Insect Sci 8:60

Athanassiou CG, Kavallieratos NG, Chintzoglou GJ, Peteinatos GG, Boukouvala MC, Petrou SS, Panoussakis EC (2008c) Effect of temperature and commodity on insecticidal efficacy of spinosad dust against Sitophilus oryzae (Coleoptera: Curculionidae) and Rhyzopertha dominica (Coleoptera: Bostrychidae). J Econ Entomol 101:976-981

Athanassiou CG, Arthur FH, Throne JE (2009) Efficacy of grain protectants against four psocid species on maize, rice and wheat. Pest Manag Sci 65:1140-1146

Chanbang Y, Arthur FH, Wilde GE, Throne JE (2007) Efficacy of diatomaceous earth and methoprene, alone and in combination, against Rhyzopertha dominica (F.) (Coleoptera: Bostrychidae). J Stored Prod Res 43:396-401

Chanbang Y, Arthur FH, Wilde GE, Throne JE, Subramanyam Bh (2008) Susceptibility of eggs and adult fecundity of the lesser grain borer, Rhyzopertha dominica, exposed to methoprene. J Insect Sci 8:48

Chintzoglou GJ, Athanassiou CG, Markoglou AN, Kavallieratos NG (2008) Influence of commodity on the effect of spinosad dust against Rhyzopertha dominica (F.) (Coleoptera: Bostrychidae) and Sitophilus oryzae (L.) (Coleoptera: Curculionidae). Intern J Pest Manag 54:277-285

Daglish GJ (2008) Impact of resistance on the efficacy of binary combinations of spinosad, chlorpyriphos-methyl and $s$-methoprene against five stored-grain beetles. J Stored Prod Res 44:71-76

Daglish GJ, Pulvirenti C (1997) Reduced fecundity of Rhyzopertha dominica (F.) (Coleoptera: Bostrichidae) following exposure of adults to methoprene. J Stored Prod Res 34:201-206

Daglish GJ, Wallbank BE (2005) Efficacy of diflubenzuron plus methoprene against Sitophilus oryzae and Rhyzopertha dominica in stored sorghum. J Stored Prod Res 41:353-360

Edwards JP, Short JE (1984) Evaluation of three compounds with insect juvenile hormone activity as grain protectants against insecticide susceptible and resistant strains of Sitophilus species (Coleoptera: Curculionidae). J Stored Prod Res 20:11-15

Fang L, Subramanyam Bh, Arthur FH (2002a) Effectiveness of spinosad on four classes of wheat against five stored product insects. J Econ Entomol 95:640-650

Fang L, Subramanyam Bh, Dolder S (2002b) Persistence and efficacy of spinosad residues in farm stored wheat. J Econ Entomol 95:1102-1109 
Getchell AI, Subramanyam Bh (2008) Immediate and delayed mortality of Rhyzopertha dominica and Sitophilus oryzae adults exposed to spinosad-treated commodities. J Econ Entomol 101:1022-1027

Greenspan L (1977) Humidity fixed points of binary saturated aqueous solutions. J Res N Bur Stand A Phys Chem 81:89-96

Huang FN, Subramanyam Bh (2007) Effectiveness of spinosad against seven major stored-grain insects on corn. Insect Sci 14:225-230

Kavallieratos NG, Athanassiou CG, Vayias BJ, Kotzamanidis S, Synodis SD (2010) Efficacy and adherence ratio of diatomaceous earth and spinosad in three wheat varieties against three storedproduct insect pests. J Stored Prod Res 46:73-80

Nayak MK, Daglish GJ (2007) Combined treatments of spinosad and chlorpyrifos-methyl for management of resistant psocid pests (Psocoptera: Liposcelididae) of stored grain. Pest Manag Sci 63:104-109

Nayak MK, Collins PJ, Reid RS (1998) Efficacy of grain protectants and phosphine against Liposcelis bostrychophila, L. entomophila and L. paeta (Psocoptera: Liposcelidae). J Econ Entomol 91:1208-1212

Nayak MK, Daglish GJ, Byrne VS (2005) Effectiveness of spinosad as a grain protectant against resistant beetle and psocid pests of stored grain in Australia. J Stored Prod Res 41:455-467

Oberlander H, Silhacek DL, Shaaya E, Ishaaya I (1997) Current status and future perspectives of the use of insect growth regulators for the control of stored product insects. J Stored Prod Res 33:1-6

Opit GP, Throne JE (2008) Population growth and development of psocid Lepinotus reticulatus at constant temperatures and relative humidities. J Econ Entomol 101:605-615

Sall J, Lehman A, Creighton L (2001) JMP start statistics. A guide to statistics and data analysis using JMP and JMP IN software. Duxbury Press, Belmont

Sokal RR, Rohlf FJ (1995) Biometry, 3rd edn. Freeman \& Company, New York

Subramanyam Bh, Toews MD, Ileleji KE, Maier DE, Thompson GD, Pitts TJ (2007) Evaluation of spinosad as a grain protectant on three Kansas farms. Crop Prot 26:1021-1030 